\title{
Osteoporosis management and fractures in the Métis of Ontario, Canada
}

\author{
Racquel Jandoc • Nathaniel Jembere • Saba Khan • \\ Storm J. Russell • Yvon Allard • Suzanne M. Cadarette
}

Received: 10 December 2014 / Accepted: 17 February 2015/Published online: 25 April 2015

(C) The Author(s) 2015. This article is published with open access at Springerlink.com

\begin{abstract}
Summary Half of Métis citizens, compared to less than $10 \%$ of the general population of Ontario, reside in northern regions, with little access to bone mineral density (BMD) testing. Métis citizens had lower sex-specific and agestandardized rates of BMD testing, yet similar rates of fracture (both sexes) and pharmacotherapy (women only).

Purpose To examine osteoporosis management and common osteoporosis-related fractures among Métis citizens compared to the general population of older adults residing in Ontario. Methods We linked healthcare (medical and pharmacy) utilization and administrative (demographic) databases with the Métis Nation of Ontario citizenship registry to estimate osteoporosis management (bone mineral density [BMD] testing, pharmacotherapy) and fractures (hip, humerus, radius/ulna) among adults aged $\geq 50$ years, from April 1, 2006 to March 31, 2011. Pharmacotherapy data were limited to residents aged $\geq 65$ years. Sex-specific and age-standardized rates were compared between the Métis and the general population. Multivariable logistic regression was used to compare rates of BMD testing after controlling for differences in age and region of residence between the Métis and the general population.
\end{abstract}

R. Jandoc $\cdot$ S. M. Cadarette

Leslie Dan Faculty of Pharmacy, University of Toronto,

Toronto, ON, Canada

N. Jembere $\cdot$ S. Khan $\cdot$ S. M. Cadarette

Institute for Clinical Evaluative Sciences, Toronto, ON, Canada

S. J. Russell • Y. Allard

Métis Nation of Ontario, Ottawa, ON, Canada

S. M. Cadarette $(\square)$

Leslie L. Dan Pharmacy Building, University of Toronto, 144

College Street, Toronto, ON M5S 3M2, Canada

e-mail: s.cadarette@utoronto.ca
Results We studied 4219 Métis citizens (55\% men), and 140 (3\%) experienced a fracture. Half of Métis citizens, compared to less than $10 \%$ of the general population of Ontario, resided in northern regions. We identified significantly lower sexspecific and age-standardized rates of BMD testing among Métis compared to the general population, yet found little difference in fracture rates (both sexes) or pharmacotherapy (women only). Differences in BMD testing disappeared after adjusting for region of residence among women yet remained significant among men.

Conclusions Despite finding significantly lower rates of osteoporosis management among men, Métis men and women were found to have similar age-standardized fracture rates to the general population.

Keywords Aboriginal $\cdot$ Fracture $\cdot$ Management $\cdot$ Métis · Osteoporosis $\cdot$ Pharmacotherapy

\section{Introduction}

The Canadian Constitution recognizes three groups of $\mathrm{Ab}$ original peoples: First Nations, Inuit, and Métis [1]. First Nations people are those who identify as North American Indians and are descendants of the original inhabitants of Canada [2]. The Inuit are Aboriginal peoples who mostly inhabit Nunatsiavut (northern coastal Labrador), Nunavik (northern Québec), the territory of Nunavut, and the Inuvialuit region of the Northwest Territories [3]. The Métis are descendants of unions between European men and First Nations women during the early 17 th century to late 19 th century [4-6], developing a culture, history, and lifestyle distinct from First Nations and Inuit people [5]. In 2011, 451,795 people identified as Métis in Canada, representing $32 \%$ of the total Aboriginal 
population [3]. Despite their significant numbers, Métis are either not identified specifically or are underrepresented in Aboriginal health research $[3,5,7,8]$. Most research has focused on First Nations; however, the Métis may differ in their health behaviours and prevalence of risk factors and disease and may require specific health interventions unique to their culture. In addition, the Métis receive significantly fewer local, provincial, and national resources for healthcare in comparison to First Nations and Inuit [9].

About one fifth $(86,015$ or $19 \%)$ of all Métis reside in Ontario, constituting the second largest provincial Métis population in Canada [3]. The Métis Nation of Ontario was established in 1993 to address the needs of this large population, and it continues to serve as the principal voice for the Métis people in the province. One key contribution of the Métis Nation of Ontario has involved establishing a voluntary registry of Métis citizens residing in Ontario [10]. Data collected and maintained by the Métis Nation of Ontario within the provincial registry has permitted a closer examination of key health challenges facing Métis people in Ontario.

In 2010, the Métis Nation of Ontario entered into a partnership with the Public Health Agency of Canada and the Institute for Clinical Evaluative Sciences to examine rates of selected chronic diseases among Métis. Results have identified higher rates of cardiovascular disease [11], diabetes [12], and chronic obstructive pulmonary disease [13] among Métis compared to the general population of Ontario. The purpose of our study was to compare rates of osteoporosis management and fractures among Métis to the general population in Ontario.

\section{Methods}

Residents of all ages in Ontario have access to publicly funded medical care and become eligible to receive pharmacy benefits at the age of 65 years. We linked healthcare (medical and pharmacy) utilization and administrative (demographic) databases from the Ontario Ministry of Health and Long-Term Care, housed at the Institute for Clinical Evaluative Sciences, to the Métis Nation of Ontario citizenship registry to compare osteoporosis management and fracture rates between Métis citizens and the general population.

Adults aged 50 or more years as of April 1, 2006 were eligible. Ontario residents not registered with the Métis Nation of Ontario were considered part of the general population. We excluded individuals residing in longterm care or whose last date of contact with the healthcare system was before April 1, 2001. We therefore focused on community-dwelling residents with some healthcare services utilization within the past 5 years. Age, sex, neighbourhood income, region of residence, and urban status were determined as of April 1, 2006. Neighbourhood income was based on census data and categorized into quintiles ranked from poorest to wealthiest. Region of residence was categorized into four main areas based on the number of densitometers (bone mineral density [BMD] machines) [14, $15]$ and sample size of Métis in each of the province's local health integration networks: 1 . Southwestern (moderate access to densitometry), 2. Southcentral (high density of densitometers and bone specialists, e.g. Hamilton and Toronto), 3 . Southeastern (moderate access to densitometry), and 4. Northern (few densitometers).

Urban residence was based on postal code and defined according to the standard geographical classification definition outlined by Statistics Canada: urban areas have a population of at least 1000 and a population density of at least 400 persons per square kilometre [16]. Fracture history (any of hip, humerus, or radius/ulna) within 6 months prior to April 1, 2006 and osteoporosis management (BMD testing and osteoporosis pharmacotherapy) within 1 year prior to April 1, 2006 were also summarized.

Osteoporosis pharmacotherapy was examined among residents aged 65 years or more and included bisphosphonates, calcitonin, denosumab, and raloxifene. Teriparatide is not covered by the provincial drug plan $[17,18]$ and thus was not considered.

Our main outcomes were 5-year rates of osteoporosis management (BMD testing and pharmacotherapy [19]) and fracture (hip, humerus, radius/ulna, or any of these). Given the known differences in osteoporosis fracture rates by sex [20] and prior evidence of an inverted U-shape between age and rates of BMD testing (rates peak among those aged 60-69 years and are lower among those aged younger than 60 and older than 69 years [14, 21]), results were stratified by sex and age group.

Crude and age-standardized rates were reported per 10,000 persons. Age-standardized rates were calculated using four age groups $(50-64,65-70,70-74$, and $\geq 75$ years of age), by direct standardization according to the 1991 Ontario census population with gamma distribution to estimate $95 \%$ confidence intervals. The direct standardization method permits the direct comparison of rates between the Métis and the general population since rates in both groups are standardized according to the age distribution of the same referent (standard) population [22]. Logistic regression was then used to examine if Métis status was independently associated with BMD testing after adjusting for age, income, region of residence, and urban status. Given that neighbourhood income, region of residence, and urban status are all based on postal code data, we also examined potential collinearity between the different possible combinations of variables using chi-square contingency tables. 


\section{Results}

We identified 4219 eligible Métis citizens and 3,822,661 eligible persons from the general population of Ontario (Fig. 1). Métis citizens were younger, had lower income status, and fewer lived in urban areas (Table 1). Almost half of Métis citizens, compared to less than $10 \%$ of the general population of Ontario, resided in northern regions, with little to no access to BMD testing.

\section{Osteoporosis management}

The proportion of Ontario residents receiving BMD testing was substantially lower among men (11\%) than among women $(55 \%)$. Although patterns of BMD testing were similar by age group among persons of the same sex (Fig. 2), fewer Métis citizens were tested after standardizing for age, Table 2. Differences in BMD testing disappeared after adjusting for neighbourhood income and region of residence among women, yet remained significant among men, Table 3. Métis men also had lower rates of osteoporosis pharmacotherapy, even after adjusting for age. In contrast, rates of osteoporosis pharmacotherapy were similar among Métis women and the general population.

\section{Fracture rates}

As expected, fracture rates increased with increasing age in both sexes (Fig. 3) and were higher among women (from $2.9 \%$ aged $50-54$ to $12.0 \%$ aged 75 and older) than among men (from $1.5 \%$ aged $50-54$ to $5.4 \%$ aged 75 and older). Crude rates of hip fracture were significantly lower among
Métis women (15.2 per 10,000 persons, 95\% CI=8.3-25.4) compared to women in the general population (35.7 per 10 , 000 persons, $95 \% \mathrm{CI}=35.4-36.1$ ), yet this difference disappeared after standardizing for age (Table 2). Similarly, we identified little difference in all sex-specific fracture rates between Métis citizens and the general population after standardizing for age.

\section{Discussion}

We identified significantly lower sex-specific and agestandardized rates of BMD testing among Métis compared to the general population, yet found little difference in fracture rates (both sexes) or pharmacotherapy (women only). Differences in BMD testing disappeared after adjusting for region of residence among women, yet remained significant among men.

Prior research identifies regional differences in BMD testing for osteoporosis based on access to BMD testing sites [23], which are largely located in urban centres [24, 25]. Given that half of Métis citizens, compared to less than $10 \%$ of the general population of Ontario, were found to reside in northern regions with little access to BMD testing, it is not surprising to find that crude as well as sex-specific and agestandardized rates of BMD testing were lower among Métis citizens compared to the general population. This is consistent with prior research on other chronic conditions that has identified lower rates of screening and fewer specialist visits among Métis that may relate to problems with access in remote areas [11-13, 26-28]. Indeed, after adjusting for regional variables (region, urban residence, neighbourhood income
Fig. 1 Study flow diagram of the Métis and the general population inclusion. Missing data refers to missing information regarding neighbourhood income, region of residence, and "urban" status

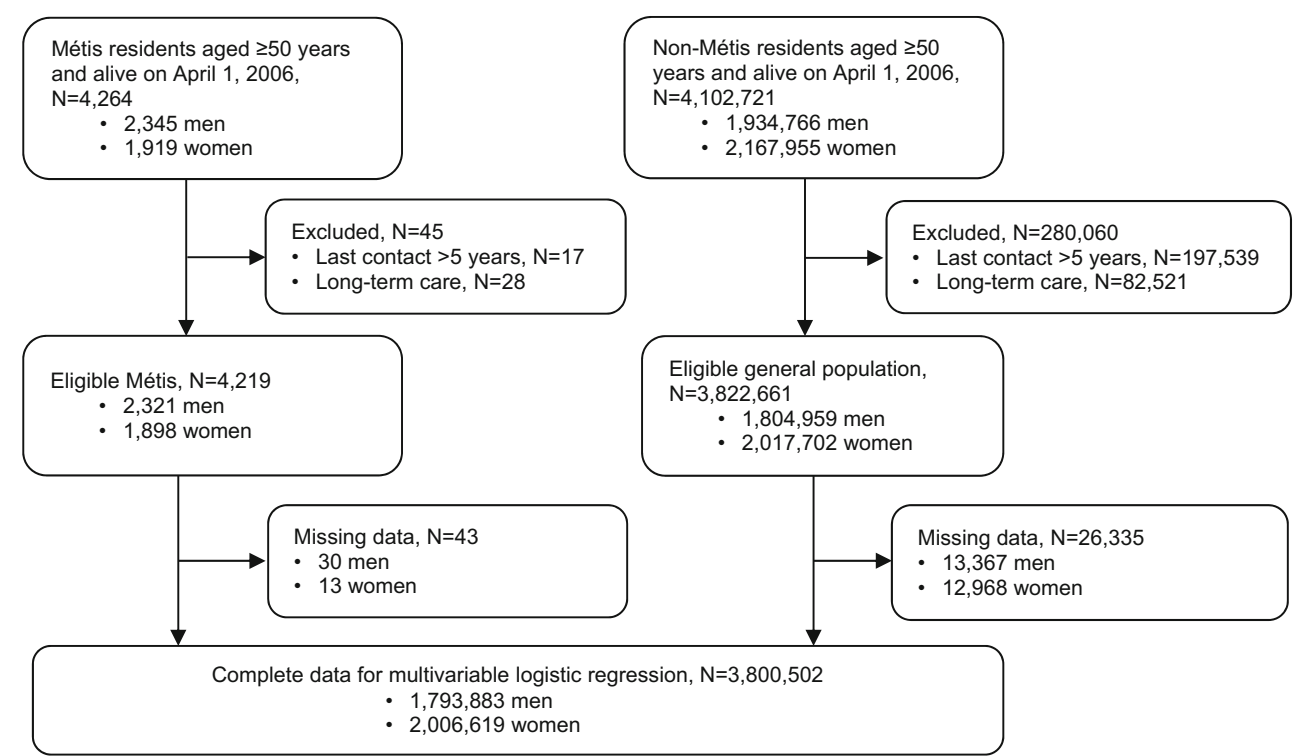


Table 1 Characteristics of the Métis and the general population, 1 April 2006

\begin{tabular}{|c|c|c|c|c|}
\hline \multirow[t]{2}{*}{ Characteristic } & \multicolumn{2}{|l|}{ Men } & \multicolumn{2}{|l|}{ Women } \\
\hline & $\begin{array}{l}\text { Métis } \\
N=2321\end{array}$ & $\begin{array}{l}\text { General } \\
N=1,804,959\end{array}$ & $\begin{array}{l}\text { Métis } \\
N=1898\end{array}$ & $\begin{array}{l}\text { General } \\
N=2,017,702\end{array}$ \\
\hline Median age, years (IQR) & $59(53-66)$ & $61(55-70)$ & $59(54-67)$ & $62(55-72)$ \\
\hline Mean age, years (SD) & $60.2(8.2)$ & $63.0(10.0)$ & $60.8(8.7)$ & $64.4(10.9)$ \\
\hline \multicolumn{5}{|l|}{ Age in years $(\%)$} \\
\hline $50-54$ & 30.9 & 24.3 & 30.5 & 22.3 \\
\hline $55-59$ & 23.6 & 21.5 & 21.7 & 19.8 \\
\hline $60-64$ & 17.3 & 15.8 & 17.5 & 14.7 \\
\hline $65-69$ & 13.2 & 12.4 & 12.5 & 12.0 \\
\hline $70-74$ & 8.7 & 10.3 & 9.1 & 10.5 \\
\hline$\geq 75$ & 6.3 & 15.7 & 8.6 & 20.7 \\
\hline \multicolumn{5}{|l|}{ Neighbourhood income quintile $(\%)^{\mathrm{a}}$} \\
\hline 1 (lowest income) & 23.5 & 18.1 & 23.5 & 19.3 \\
\hline 2 & 20.7 & 19.9 & 21.6 & 20.4 \\
\hline 3 & 21.4 & 19.5 & 19.3 & 19.4 \\
\hline 4 & 17.7 & 20.4 & 18.8 & 19.8 \\
\hline 5 (highest income) & 16.7 & 22.2 & 16.8 & 21.1 \\
\hline \multicolumn{5}{|l|}{ Region of residence $(\%)^{\mathrm{a}}$} \\
\hline Southwestern & 7.1 & 18.3 & 7.9 & 18.3 \\
\hline Erie St. Clair & 2.4 & 5.4 & 2.1 & 5.3 \\
\hline South West & 3.5 & 7.8 & 3.6 & 7.9 \\
\hline Waterloo Wellington & 1.2 & 5.1 & 2.2 & 5.1 \\
\hline Southcentral & 9.2 & 44.7 & 13.5 & 45.0 \\
\hline Hamilton Niagara Haldimand Brant & 4.0 & 11.6 & 6.9 & 11.8 \\
\hline Central West & 0.9 & 5.0 & 1.0 & 4.8 \\
\hline Mississauga Halton & 1.1 & 7.6 & 1.9 & 7.5 \\
\hline Toronto Central & 1.5 & 8.5 & 1.8 & 8.8 \\
\hline Central & 1.7 & 11.9 & 2.0 & 12.1 \\
\hline Southeastern & 33.0 & 29.5 & 34.6 & 29.6 \\
\hline Central East & 4.7 & 11.8 & 4.6 & 11.9 \\
\hline South East & 3.6 & 4.5 & 2.4 & 4.5 \\
\hline Champlain & 4.5 & 9.5 & 4.8 & 9.6 \\
\hline North Simcoe Muskoka & 20.3 & 3.7 & 22.8 & 3.6 \\
\hline Northern & 50.6 & 7.5 & 44.0 & 7.1 \\
\hline North East & 36.1 & 5.4 & 29.4 & 5.2 \\
\hline North West & 14.5 & 2.1 & 14.6 & 1.9 \\
\hline Urban residence $(\%)^{\mathrm{a}}$ & 62.4 & 85.5 & 68.3 & 86.6 \\
\hline Fracture history $^{\mathrm{b}}$ & 0.1 & 0.3 & 0.7 & 0.6 \\
\hline \multicolumn{5}{|l|}{ Osteoporosis management $^{c}$} \\
\hline Bone mineral density test & 1.5 & 2.5 & 16.4 & 19.5 \\
\hline Pharmacotherapy (aged $\geq 65)^{\mathrm{d}}$ & 1.7 & 4.1 & 22.6 & 26.3 \\
\hline
\end{tabular}

${ }^{a}$ Proportions adjusted for missing data for neighbourhood income (1 \% Métis and $0.7 \%$ general population) and region ( $0.5 \%$ Métis and $0.4 \%$ general population)

${ }^{\mathrm{b}}$ Hip, humerus, or radius/ulna fracture within 6 months prior to April 1, 2006

${ }^{\mathrm{c}} 1$ year lookback from April 1, 2006 (April 1, 2005 to March 31, 2006)

${ }^{\mathrm{d}}$ Osteoporosis pharmacotherapy includes bisphosphonates, calcitonin, denosumab, and raloxifene 

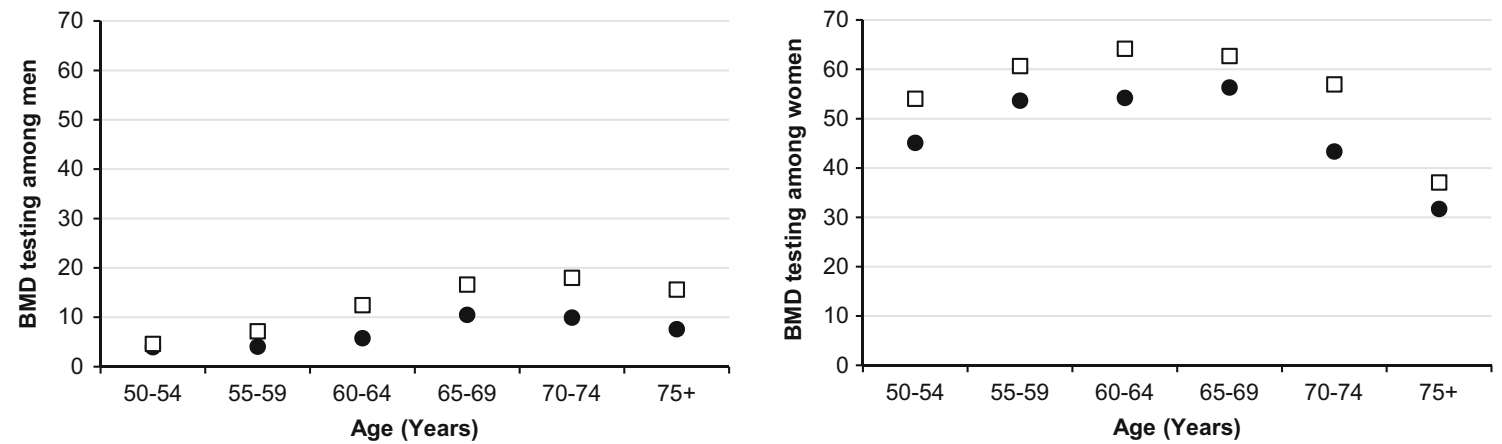

Fig. 2 Five-year bone mineral density (BMD) testing rates among the Métis (closed circle) and the general population (open square), by age group, stratified by sex. $95 \%$ confidence intervals for Métis estimates are wide and overlap with the general population in all comparisons

Table 2 Five-year rates ${ }^{\mathrm{a}}$ of osteoporosis management and fractures in the Métis and the general population of Ontario

\begin{tabular}{|c|c|c|c|c|}
\hline \multirow[t]{2}{*}{ Outcome of interest } & \multicolumn{2}{|l|}{ Men } & \multicolumn{2}{|l|}{ Women } \\
\hline & $\begin{array}{l}\text { Métis } \\
N=2321\end{array}$ & $\begin{array}{l}\text { General population } \\
N=180,959\end{array}$ & $\begin{array}{l}\text { Métis } \\
N=1898\end{array}$ & $\begin{array}{l}\text { General population } \\
N=2,017,702\end{array}$ \\
\hline \multicolumn{5}{|l|}{ Osteoporosis management } \\
\hline \multicolumn{5}{|l|}{ 1. Bone mineral density test } \\
\hline$N$ & 136 & 197,730 & 923 & $1,102,997$ \\
\hline Crude rate $(95 \% \mathrm{CI})$ & $122.4(102.8-144.7)$ & $230.1(229.1-231.1)$ & $999.1(935.7-1065.7)$ & $1137.1(1134.9-1139.2)$ \\
\hline Age-standardized rate $(95 \% \mathrm{CI})$ & $134.2(110.9-160.9)$ & $245.5(244.4-246.6)^{*}$ & $969.1(889.3-1054.1)$ & $1135.1(1132.9-1137.3)^{*}$ \\
\hline \multicolumn{5}{|c|}{ 2. Osteoporosis pharmacotherapy (aged $\geq 65)^{\mathrm{b}}$} \\
\hline$N$ & 35 & 63,205 & 203 & 345,213 \\
\hline Crude rate $(95 \% \mathrm{CI})$ & $114.1(79.5-158.6)$ & $201.4(199.8-203.0)$ & $751.2(651.4-861.9)$ & $855.7(852.8-858.5)$ \\
\hline Age-standardized rate $(95 \% \mathrm{CI})$ & $125.5(82.8-182.4)$ & $198.7(197.0-200.4)^{*}$ & $758.4(626.3-910.1)$ & $850.9(847.9-854.0)$ \\
\hline \multicolumn{5}{|c|}{ 3. Osteoporosis management (BMD test or pharmacotherapy) ${ }^{b}$} \\
\hline$N$ & 150 & 219,668 & 993 & $1,201,199$ \\
\hline Crude rate $(95 \% \mathrm{CI})$ & $134.9(114.2-158.2)$ & $255.6(254.5-256.7)$ & $1074.9(1009.1-1143.9)$ & $1238.4(1236.2-1240.6)$ \\
\hline Age-standardized rate $(95 \% \mathrm{CI})$ & $161.3(133.4-193.2)$ & $274.6(273.4-275.8)^{*}$ & $1093.2(1007.6-1184.0)$ & $1254.3(1251.9-1256.6)^{*}$ \\
\hline \multicolumn{5}{|l|}{ Fractures } \\
\hline \multicolumn{5}{|l|}{ 1. Hip fracture } \\
\hline$N$ & 16 & 14,670 & 14 & 34,675 \\
\hline Crude rate $(95 \% \mathrm{CI})$ & $14.3(8.2-23.2)$ & $17.1(16.8-17.4)$ & $15.2(8.3-25.4)$ & $35.7(35.4-36.1)$ \\
\hline Age-standardized rate $(95 \% \mathrm{CI})$ & $24.7(11.7-46.0)$ & $18.8(18.4-19.1)$ & $26.7(13.3-47.9)$ & $41.1(40.5-41.6)$ \\
\hline \multicolumn{5}{|l|}{ 2. Humerus fracture } \\
\hline$N$ & 12 & 11,278 & 22 & 30,070 \\
\hline Crude rate $(95 \% \mathrm{CI})$ & $10.7(5.5-18.7)$ & $13.1(12.9-13.4)$ & $23.8(14.9-36.1)$ & $31.0(30.7-31.4)$ \\
\hline Age-standardized rate $(95 \% \mathrm{CI})$ & $13.5(5.9-26.3)$ & $13.7(13.4-14.0)$ & $25.2(14.9-40.0)$ & $33.4(33.0-33.9)$ \\
\hline \multicolumn{5}{|l|}{ 3. Radius or ulna fracture } \\
\hline$N$ & 21 & 20,452 & 65 & 63,796 \\
\hline Crude rate $(95 \% \mathrm{CI})$ & $18.8(11.6-28.7)$ & $23.8(23.5-24.1)$ & $70.4(54.3-89.7)$ & $65.8(65.3-66.3)$ \\
\hline Age-standardized rate $(95 \% \mathrm{CI})$ & $19.2(11.2-30.7)$ & $24.1(23.7-24.4)$ & $77.8(57.6-102.7)$ & $68.2(67.6-68.7)$ \\
\hline \multicolumn{5}{|c|}{ 4. Any fracture (hip, humerus, radius/ulna) } \\
\hline$N$ & 45 & 43,132 & 95 & 116,539 \\
\hline Crude rate $(95 \% \mathrm{CI})$ & $40.2(29.3-53.8)$ & $50.2(49.7-50.7)$ & $102.8(83.2-125.7)$ & $120.1(119.4-120.8)$ \\
\hline Age-standardized rate $(95 \% \mathrm{CI})$ & $53.8(35.8-77.8)$ & $52.5(52.0-53.1)$ & $122.5(95.8-154.4)$ & $128.9(128.1-129.8)$ \\
\hline
\end{tabular}

*Differences in age-standardized rates are statistically significant, $p<0.05$

${ }^{a}$ Rates per 10,000 people; age-standardized using sex-specific direct standardization to the 1991 Canadian population

${ }^{\mathrm{b}}$ Osteoporosis pharmacotherapy includes bisphosphonates, calcitonin, denosumab, and raloxifene 
Table 3 Odds ratio estimates for bone mineral density (BMD) testing among Métis vs. general population of Ontario by sex; unadjusted and adjusted for age, income, and region of residence

\begin{tabular}{|c|c|c|c|c|}
\hline \multirow[t]{2}{*}{ Characteristic } & \multicolumn{2}{|l|}{ Men } & \multicolumn{2}{|l|}{ Women } \\
\hline & $\begin{array}{l}\text { Unadjusted } \\
\text { OR }(95 \% \text { CI }) \\
N=1,793,883\end{array}$ & $\begin{array}{l}\text { Adjusted } \\
\text { OR }(95 \% \text { CI }) \\
N=1,793,883\end{array}$ & $\begin{array}{l}\text { Unadjusted } \\
\text { OR }(95 \% \text { CI }) \\
N=2,006,619\end{array}$ & $\begin{array}{l}\text { Adjusted } \\
\text { OR }(95 \% \text { CI }) \\
N=2,006,619\end{array}$ \\
\hline Métis citizen & $0.51(0.43-0.61)$ & $0.82(0.69-0.98)$ & $0.78(0.71-0.86)$ & $0.95(0.87-1.04)$ \\
\hline \multicolumn{5}{|l|}{ Age in years } \\
\hline $50-54$ & 1 & 1 & 1 & 1 \\
\hline $55-59$ & $1.60(1.57-1.63)$ & $1.61(1.58-1.64)$ & $1.31(1.30-1.33)$ & $1.33(1.32-1.34)$ \\
\hline $60-64$ & $2.97(2.91-3.02)$ & $3.03(2.98-3.08)$ & $1.53(1.51-1.54)$ & $1.57(1.56-1.59)$ \\
\hline $65-69$ & $4.15(4.08-4.23)$ & $4.26(4.19-4.34)$ & $1.43(1.42-1.44)$ & $1.48(1.46-1.50)$ \\
\hline $70-74$ & $4.56(4.48-4.65)$ & $4.69(4.60-4.77)$ & $1.12(1.11-1.13)$ & $1.16(1.15-1.17)$ \\
\hline$\geq 75$ & $3.84(3.77-3.91)$ & $3.91(3.84-3.98)$ & $0.50(0.49-0.50)$ & $0.51(0.50-0.51)$ \\
\hline \multicolumn{5}{|l|}{ Neighbourhood income quintile } \\
\hline 1 (lowest income) & 1 & 1 & 1 & 1 \\
\hline 2 & $1.05(1.04-1.07)$ & $1.03(1.02-1.05)$ & $1.17(1.16-1.18)$ & $1.14(1.13-1.15)$ \\
\hline 3 & $1.04(1.02-1.06)$ & $1.05(1.03-1.06)$ & $1.27(1.26-1.28)$ & $1.23(1.22-1.24)$ \\
\hline 4 & $1.06(1.04-1.07)$ & $1.06(1.04-1.07)$ & $1.41(1.39-1.42)$ & $1.32(1.31-1.33)$ \\
\hline 5 (highest income) & $1.11(1.10-1.13)$ & $1.10(1.09-1.12)$ & $1.58(1.57-1.60)$ & $1.47(1.46-1.49)$ \\
\hline \multicolumn{5}{|l|}{ Region of residence } \\
\hline \multicolumn{5}{|l|}{ Southwestern ${ }^{\mathrm{a}}$} \\
\hline Erie St. Clair & 1 & 1 & 1 & 1 \\
\hline South West & $1.30(1.26-1.35)$ & $1.36(1.32-1.41)$ & $1.07(1.06-1.09)$ & $1.11(1.09-1.12)$ \\
\hline Waterloo Wellington & $1.72(1.66-1.78)$ & $1.79(1.73-1.85)$ & $1.52(1.49-1.54)$ & $1.53(1.50-1.55)$ \\
\hline \multicolumn{5}{|l|}{ Southcentral $^{\mathrm{a}}$} \\
\hline Hamilton Niagara Haldimand Brant & $2.31(2.24-2.38)$ & $2.29(2.23-2.36)$ & $1.80(1.77-1.82)$ & $1.85(1.82-1.88)$ \\
\hline Central West & $1.93(1.87-2.00)$ & $2.04(1.97-2.11)$ & $1.78(1.75-1.81)$ & $1.73(1.70-1.76$ \\
\hline Mississauga Halton & $2.08(2.02-2.15)$ & $2.17(2.11-2.24)$ & $2.30(2.27-2.34)$ & $2.19(2.16-2.23)$ \\
\hline Toronto Central & $2.43(2.36-2.51)$ & $2.51(2.43-2.59)$ & $1.87(1.84-1.90)$ & $1.91(1.88-1.94)$ \\
\hline Central & $2.66(2.58-2.73)$ & $2.71(2.63-2.79)$ & $2.21(2.17-2.34)$ & $2.18(2.15-2.22)$ \\
\hline \multicolumn{5}{|l|}{ Southeastern $^{\mathrm{a}}$} \\
\hline Central East & $2.16(2.10-2.23)$ & $2.23(2.16-2.29)$ & $1.75(1.73-1.78)$ & $1.81(1.78-1.84)$ \\
\hline South East & $1.49(1.44-1.55)$ & $1.54(1.49-1.60)$ & $1.17(1.15-1.19)$ & $1.23(1.21-1.25)$ \\
\hline Champlain & $1.65(1.60-1.70)$ & $1.73(1.68-1.78)$ & $1.62(1.60-1.65)$ & $1.63(1.61-1.66$ \\
\hline North Simcoe Muskoka & $1.46(1.41-1.52)$ & $1.52(1.46-1.58)$ & $1.56(1.53-1.59)$ & $1.61(1.57-1.64)$ \\
\hline \multicolumn{5}{|l|}{ Northern $^{\mathrm{a}}$} \\
\hline North East & $1.17(1.13-1.22)$ & $1.22(1.18-1.26)$ & $0.93(0.91-0.95)$ & $0.95(0.93-0.97)$ \\
\hline North West & $0.58(0.55-0.62)$ & $0.62(0.58-0.66)$ & $0.72(0.71-0.74)$ & $0.73(0.71-0.75)$ \\
\hline Urban residence & $1.51(1.49-1.53)$ & $1.18(1.16-1.20)$ & $1.41(1.40-1.42)$ & $1.11(1.10-1.12)$ \\
\hline
\end{tabular}

${ }^{\text {a }}$ Region of residence was categorized into four main areas based on the number of densitometers (BMD machines) [14, 15] and sample size of Métis in each of the province's local health integration networks: Southwestern (moderate access to densitometry), Southcentral (high density of densitometers and bone specialists, e.g. Hamilton and Toronto), Southeastern (moderate access to densitometry), and Northern (few densitometers)

quintile), differences in rates of BMD testing disappeared among women. However, differences persisted among men. Prior research identifies higher rates of osteoporosis risk factors such as cardiovascular disease, chronic obstructive pulmonary disease, and diabetes among Métis compared to the general population of Ontario [11-13], and thus, the finding that BMD testing rates were lower among Métis men after adjusting for regional characteristics is puzzling. Indeed, our finding that Métis men had lower age-standardized rates of osteoporosis pharmacotherapy suggests a potential gender gap. Prior research identifies a tight link between BMD testing and osteoporosis treatment initiation [25]. It is thus not surprising to find that lower rates of BMD testing among men would translate into lower rates of pharmacoprevention. Prior 


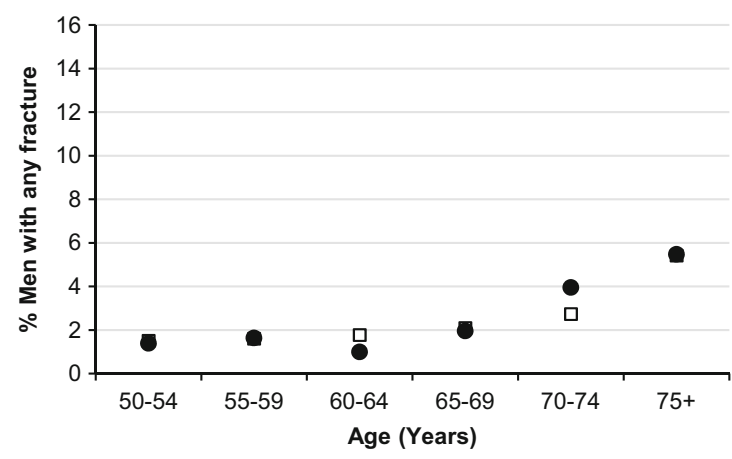

Fig. 3 Five-year fracture rates among the Métis (closed circle) and the general population (open square), by age group, stratified by sex. Any fracture refers to a fracture of the hip, humerus, or radius/ulna. The $95 \%$

research has also found that men have lower rates of postfracture treatment and glucocorticoid-induced osteoporosis management compared to women $[29,30]$. It is thus particularly interesting to find that Métis men have lower rates of BMD testing after adjusting for regional differences in access, compared with men in the general population. Further research to better understand the reasons for lower rates of BMD testing and osteoporosis treatment among Métis men compared to the general population of men is of interest.

Access to BMD testing has been shown to impact pharmacotherapy [25] and thus is proposed to lead to potential inequities in fracture prevention. One interpretation of our findings may therefore be to improve access to BMD testing in northern and rural areas of Ontario. However, despite finding lower age-adjusted rates of BMD testing (both sexes) and pharmacotherapy (men only) among Métis citizens compared to the general population, fracture rates were found to be similar. Although this finding is comforting, our results are limited by not including vertebral fractures. Vertebral fractures are the most common type of osteoporotic fracture and cause significant morbidity [20]; however, less than half come to clinical attention $[31,32]$. For this reason, healthcare administrative data are limited in ability to capture vertebral fractures. It is thus possible that a closer examination with X-rays could identify significant differences in vertebral fractures and thus osteoporosis morbidity, particularly among Métis men. Nonetheless, our finding of little difference in fracture rates between the Métis population and general population of Ontario is consistent with prior research that found similar prevalence of osteoporosis or fracture among Métis and all other residents in Manitoba [33]. However, our results contradict findings from research conducted with larger groups of $\mathrm{Ab}$ original peoples in Manitoba that document significantly higher fracture rates among First Nations after adjusting for age, sex, income, and geographical residence area [34]. Both studies from Manitoba included vertebral fractures, and differences in vertebral fractures among First Nations were largely identified in younger age groups compared to our study that focused on adults aged 50 or more years [34]. Higher fracture

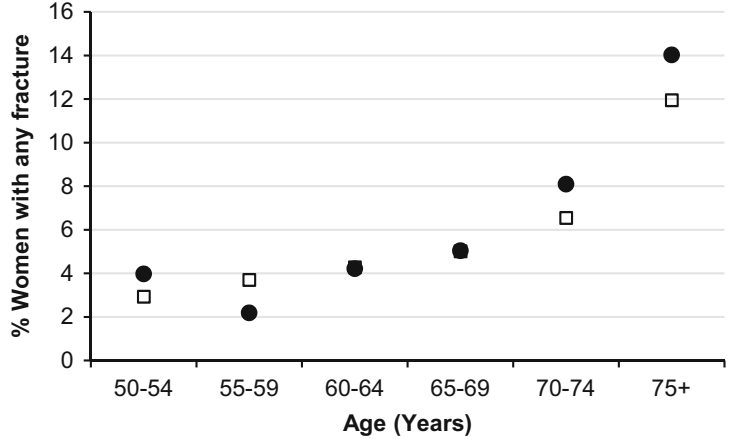

confidence intervals for Métis estimates are wide and overlap with the general population in all comparisons

rates among First Nations people in Manitoba are proposed to be related to higher prevalence of diabetes, comorbidity, and substance abuse [35] and a higher rate of accidental and non-accidental trauma [34]. Further research into the burden of osteoporosis among distinct groups of $\mathrm{Ab}$ original peoples (First Nations, Inuit, and Métis) is of interest. Results from Manitoba identified that First Nations people are less likely to receive a BMD test or pharmacotherapy within 6 months post-fracture [36], yet are at higher risk for post-fracture mortality [37]. Due to the small number of Métis citizens with fractures in our study, we were unable to examine post-fracture osteoporosis management or adherence to therapy.

We acknowledge that our study is subject to some limitations. First, given that the Métis citizenship registry is voluntary and requires individuals to provide proof of ancestry, it may not capture the entire Métis population in Ontario and thus misclassify some Métis in the general population. In comparison to the 2011 National Household Survey, our cohort of Métis citizens represents approximately $25 \%$ of the equivalently aged Métis in Ontario and is represented by more men (55 vs. $49 \%$ in the National Household Survey) [3]. Registration with the Métis Nation of Ontario permits citizens to apply for Harvesters Certification that allows holders to hunt and fish [38], a benefit that may be more appealing to male Métis. Nonetheless, by completing analyses separately for men and women and standardizing by age, we were able to adjust for any sex- and age-related differences. In addition, although Métis people not registered with the Métis Nation of Ontario, as well as other Aboriginal peoples (First Nations and Inuit), would be included with the general population estimates, we anticipate little overall impact on estimates of osteoporosis management in the general population since these Aboriginal groups are few in number compared to the large population of older adults in Ontario. Second, the Ontario Drug Benefit database is limited to individuals aged $\geq 65$ years, and thus, we did not have pharmacy data for younger patients. Although we could have restricted our study to persons aged $\geq 65$ years, including men and women aged 50 or more years 
in our study permitted a more comprehensive comparison of BMD testing and fracture rates. Third, our study was limited by a relatively small sample size of Métis men and women aged 50 or more years, with few overall fractures, and we were unable to examine other osteoporosis risk factors, such as glucocorticoid exposure that may differentially impact osteoporosis management in the Métis and the general population. Finally, our data did not capture vertebral fractures, and thus, we may underestimate differences in rates of some osteoporotic fractures between Métis citizens and the general population. Despite these limitations, we have significant strength in our ability to leverage data for the province of Ontario and in working with the Métis Nation of Ontario and the Public Health Agency of Ontario in their efforts to better understand Métis health.

As the Métis Nation of Ontario registry and other Métis registries grow across Canada, future research may be able to examine comparative rates of osteoporosis management and fractures in a larger and more representative sample of Métis citizens, and in particular, post-fracture osteoporosis management. We recommend that future research aim to clarify the burden of osteoporosis management among different Aboriginal groups, particularly among men; and examine whether regional variation in access to services, such as BMD testing in rural and remote locations, translate into important differences in post-fracture management and adherence to osteoporosis pharmacotherapy.

Acknowledgments The Métis Nation of Ontario would like to thank the Public Health Agency of Canada for providing funding for this study through the "Capacity Building for Public Health Surveillance" initiative. This research was completed at the Institute for Clinical Evaluative Sciences (ICES), which is funded by an annual grant from the Ontario Ministry of Health and Long-Term Care (MOHLTC). Dr. Cadarette was supported by a Canadian Institutes of Health Research (CIHR) New Investigator Award in Aging and Osteoporosis (MSH-95364). The opinions, results, and conclusions reported in this paper are those of the authors and are independent from the funding sources. No endorsement by ICES, CIHR, or the Ontario MOHLTC is intended or should be inferred.

\section{Conflicts of interest None.}

Open Access This article is distributed under the terms of the Creative Commons Attribution-NonCommercial 4.0 International License (http://creativecommons.org/licenses/by-nc/4.0/), which permits any noncommercial use, distribution, and reproduction in any medium, provided you give appropriate credit to the original author(s) and the source, provide a link to the Creative Commons license, and indicate if changes were made.

\section{References}

1. Government of Canada, Supplies and Service: Constitution Act, 1982 Section 35. http://www.edu.gov.mb.ca/k12/cur/socstud/ foundation_gr6/blms/6-3-2c.pdf Accessed Februrary 172014
2. Aboriginal Affairs and Northern Development Canada (2014) First Nations people in Canada. http://www.aadnc-aandc.gc.ca/eng/ 1303134042666/1303134337338 Accessed January 52015

3. Statistics Canada (2013) Aboriginal Peoples in Canada: First Nations People, Metis, and Inuit. National Household Survey, 2011. Minister of Industry, Ottawa

4. Métis Nation of Ontario (2014) Who are the Métis. http://www. metisnation.org/culture-heritage/who-are-the-metis Accessed February 102014

5. Martens PJ, Bartlett JG, Prior HJ, Sanguins J, Burchill CA, Burland EM, Carter S (2011) What is the comparative health status and associated risk factors for the Metis? A population-based study in Manitoba, Canada. BMC Public Health 11:814

6. Bruce SG, Kliewer EV, Young TK, Mayer T, Wajda A (2003) Diabetes among the Métis of Canada: defining the population, estimating the disease. Can J Diabetes 27:442-448

7. Kumar MB, Wesche S, McGuire C (2012) Trends in Metis-related health research (1980-2009): identification of research gaps. Can J Public Health 103:23-28

8. Young TK (2003) Review of research on aboriginal populations in Canada: relevance to their health needs. BMJ 327:419-422

9. Evans M, Anderson C, Dietrich D, Bourassa C, Logan T, Berg LD, Devolder E (2012) Funding and ethics in Métis community-based research: the complications of a contemporary context. Int J Crit Indigenous Stud 5:54-66

10. Métis Nation of Ontario (2014) About the Métis Nation of Ontario. http://www.metisnation.org/about-the-mno/the-metis-nation-ofontario Accessed February 102014

11. Institute for Clinical Evaluative Sciences, Métis Nation of Ontario (2012) Cardiovascular disease in the Métis Nation of Ontario

12. Shah BR, Cauch-Dudek K, Pigeau L (2011) Diabetes prevalence and care in the Metis population of Ontario, Canada. Diabetes Care 34: 2555-2556

13. Gershon AS, Khan S, Klein-Geltink J et al (2014) Asthma and chronic obstructive pulmonary disease (COPD) prevalence and health services use in Ontario Metis: a population-based cohort study. PLoS One 9:e95899

14. Jaglal SB, McIsaac WJ, Hawker G, Jaakkimainen L, Cadarette SM, Chan BT (2000) Patterns of use of the bone mineral density test in Ontario, 1992-1998. CMAJ 163:1139-1143

15. Medical Advisory Secretariat (2006) Utilization of DXA bone mineral densitometry in Ontario: an evidence-based analysis. Ont Health Technol Assess Series 6(20):28-32

16. Ontario Ministry of Health and Long-Term Care (2012) Health analyst's toolkit. Queen's Printer for Ontario, Toronto

17. Cadarette SM, Carney G, Baek D, Gunraj N, Paterson JM, Dormuth CR (2012) Osteoporosis medication prescribing in British Columbia and Ontario: impact of public drug coverage. Osteoporos Int 23: $1475-1480$

18. Ontario Ministry of Health and Long-Term Care Formulary Search: Ontario Drug Benefit formulary/comparative drug index. https:// www.healthinfo.moh.gov.on.ca/formulary/index.jsp Accessed February 112014

19. Cadarette SM, Jaglal SB, Raman-Wilms L, Beaton DE, Paterson JM (2011) Osteoporosis quality indicators using healthcare utilization data. Osteoporos Int 22:1335-1342

20. Cadarette SM, Burden AM (2011) The burden of osteoporosis in Canada. Can Pharm J 144:S3

21. Jaglal SB, Weller I, Mamdani M, Hawker G, Kreder H, Jaakkimainen L, Adachi JD (2005) Population trends in BMD testing, treatment, and hip and wrist fracture rates: are the hip fracture projections wrong? J Bone Miner Res 20:898-905

22. Pagano M, Guauvreau K (1993) Principles of biostatistics. Wadsworth, Inc., California

23. Curtis JR, Laster A, Becker DJ et al (2009) The geographic availability and associated utilization of dual-energy X-ray absorptiometry 
(DXA) testing among older persons in the United States. Osteoporos Int 20:1553-1561

24. Cadarette SM, Jaglal SB, Hawker GA (2005) Fracture prevalence and treatment with bone-sparing agents: are there urban-rural differences? A population-based study in Ontario, Canada. J Rheumatol 32:550-558

25. Cadarette SM, Gignac MA, Jaglal SB, Beaton DE, Hawker GA (2007) Access to osteoporosis treatment is critically linked to access to dual-energy x-ray absorptiometry testing. Med Care 45:896-901

26. Wang L, Tormala T (2014) Integrating spatial and aspatial factors in measuring accessibility to primary health care physicians: a case study of Aboriginal population in Sudbury, Canada. J Community Med Health Educ 4:284. doi: 210.4172/2161-0711.1000284

27. Withrow DR, Amartey A, Marrett LD (2014) Cancer risk factors and screening in the off-reserve First Nations, Metis and non-Aboriginal populations of Ontario. Chronic Dis Inj Can 34:103-112

28. Young S, Candido E, Theis B, L M (2014) Prevention and surveillance, prevention and cancer control, Cancer Care Ontario CCO. Cancer risk factors in Ontario: Alcohol. Aboriginal Peoples (off-reserve). Cancer Care Ontario, Action Cancer Ontario, Toronto

29. Elliot-Gibson V, Bogoch ER, Jamal SA, Beaton DE (2004) Practice patterns in the diagnosis and treatment of osteoporosis after a fragility fracture: a systematic review. Osteoporos Int 15:767-778

30. Albaum JM, Youn S, Levesque LE, Gershon AS, Cadarette SM (2014) Osteoporosis management among chronic glucocorticoid users: a systematic review. J Popul Ther Clin Pharmacol 21:e486-e504

31. Bliuc D, Nguyen ND, Milch VE, Nguyen TV, Eisman JA, Center JR (2009) Mortality risk associated with low-trauma osteoporotic fracture and subsequent fracture in men and women. JAMA 301: $513-521$

32. Cooper C, Atkinson EJ, O'Fallon WM, Melton LJ 3rd (1992) Incidence of clinically diagnosed vertebral fractures: a populationbased study in Rochester, Minnesota, 1985-1989. J Bone Miner Res 7:221-227

33. Manitoba Centre for Health Policy, Manitoba Métis Federation (2010) Profile of Métis health status and healthcare utilization in Manitoba: a population-based study. Winnipeg: Manitoba Centre for Health Policy

34. Leslie WD, Derksen S, Metge C, Lix LM, Salamon EA, Wood Steiman P, Roos LL (2004) Fracture risk among First Nations people: a retrospective matched cohort study. CMAJ 171:869-873

35. Leslie WD, Derksen S, Prior HJ, Lix LM, Metge C, O’Neil J (2006) The interaction of ethnicity and chronic disease as risk factors for osteoporotic fractures: a comparison in Canadian Aboriginals and non-Aboriginals. Osteoporos Int 17:1358-1368

36. Leslie WD, Brennan SL, Prior HJ, Lix LM, Metge C, Elias B (2012) The post-fracture care gap among Canadian First Nations peoples: a retrospective cohort study. Osteoporos Int 23:929-936

37. Leslie WD, Brennan SL, Prior HJ, Lix LM, Metge C, Elias B (2013) The contributions of First Nations ethnicity, income, and delays in surgery on mortality post-fracture: a population-based analysis. Osteoporos Int 24:1247-1256

38. Métis Nation of Ontario (2015) MNO Registry Policy. http://www. metisnation.org/media/503322/mno\%20registry\%20policyapproved\%20by\%202014\%20aga.pdf Accessed January 62015 